\title{
Digital Video Broadcasting-Return Channel via Satellite (DVB-RCS) Implementation in Ghana for Maritime and Other Mobile Communication
}

\author{
Bernard Adjei-Frimpong \\ Kumasi polytechnic, Ghana
}

\author{
Kingsley Akom \\ Kumasi polytechnic, Ghana
}

\author{
George Asante \\ University of Education, \\ Winneba \\ Kumasi-Ghana
}

\begin{abstract}
This paper presents solution to developing trends in next generation satellite communication technologies which have significant implication on maritime and mobile communication systems based on specific need and significant broadband connectivity, quality delivery of service and interactivity in Ghana.

Due to the narrow bandwidth of terrestrial access links and the enormous costs for increasing bandwidth in remote location and enabling IP-multicast streaming for access, a satellite overlay network using Digital Video Broadcasting Return channel service (DVB-RCS) technology will be examined and the infrastructure required for communication, navigation and surveillance selected for implementation. The satellite network will delivers live streaming of voice, data and video over IP contents simultaneously to numerous users in every remote location. An overview of the technical aspect will be implemented in order to establish quality infrastructures, allowing the services of DVB-RCS distributed via satellite.
\end{abstract}

The paper also outlines DVB-RCS benefits which will be achieved in practice, based on requirements from implementing these applications in urban, rural and mobile environments including maritime solutions.

\section{General Terms}

DVB-RCS, Video Broadcasting, Maritime

\section{Keywords}

DVB-RCS, Video Broadcasting, Maritime, VOIP, VDVOIP

\section{INTRODUCTION}

Availability and wide spread interest for information and communication technologies for users in Ghana has become a challenge, and it is driving the search for new approaches to cost effective and easy access to carry information to urban, rural and remote regions of the country to enhance information and communication technologies. In 2010, the national communication authority produced a report to the Government on "migration from analogue to digital broadcasting in Ghana" outlining the reason and modalities for adopting digital transmission with emphasis on meeting international standards. The best innovative technology for this application is the development of Digital Video Broadcasting via satellite and ground network for fixed and mobile applications[3]. Digital Video Broadcasting-Return Channel via satellite (DVB-RCS) was developed in the late 2000, as an open standard by the European Telecommunication standard institute (ETSI) for satellite interactive broadband network services[14]. This standard is used to provide multimedia service and real time or non- real time voice, data, voice over IP (VoIP), video streaming, video Conferencing interconnectivity between users, e-commerce, and e-governance. The system delivers quality services and has robust potentials in technology, which service providers can adopt to accelerate economies of scale and create a shorter timeframe for market and low cost solutions [6].

Standardization of DVB-RCS and interoperability of the satellite community over the past year is a major milestone for developing reliable, efficient and low cost satellite equipments. The positive outcome is bridging the existing digital divide through the provision of broadband access to multimedia services in low terrestrial area[4]. DVB-RCS can support applications at fixed locations in urban, suburban and rural environments, as well as on mobile platforms such as stationary and moving vehicles, manned and unmanned aircraft and ships [12].

The entire network for DVB-RCS is dived into three sections that is: space segment, ground segment and the user segment. The ground segment communicates via the satellite and interfaces with the terrestrial networks which the satellite serves, and it is called user segment. DVB-RCS is very robust with rapid installation and highly effective for IPTV, highspeed Internet access, Voice over IP (VoIP) and Voice, Data and Video over IP (VDVoIP) for maritime and mobile communication applications [6].

\section{RELATED WORK}

Terrestrial Wireless communication network which allow users to initiate and receive phone calls, also include service based on data transmission and multimedia. In an event of emergency, relief response teams need to be able to rely on robust and reliable communications [1]. In recent times, terrestrial communication system has been the backbone for the provision of communication to maritime and mobile application systems. This provision has technical limitations due to increase bandwidth and cost. These wireless communication systems are also based on MF, HF, VHF radios for ships to communicate onshore and offshore and are not able to support other services like e-Navigation due to inadequate bandwidth. This conventional maritime communication system is based on voice communication, which is using radio devices of MF, HF, VHF systems [9]. The limitations have prompted research into various ways of employing appropriate technology to improve bandwidth, reduce cost and enhance quality of communication and transmission of data, because improved communication technology is needed for large multimedia services; VoIP, VDVoIP, navigation and control. This has triggered renewed 
interest for reliable communication techniques, thereby emphasizing the challenges embodied by network properties such as rapid deployment, self sustainability and interoperability as well as flexibility, scalability, low cost, increase bandwidth and reliable services [17].

Thus, the wide area coverage and availability in rural and remote location make satellite IP/DVB base network application very promising for all for forms of data, voice, videoconferencing, VoIP, VDVoIP, navigation and control. This satellite network technology for maritime and mobile applications is important because, there are areas on earth which cannot be covered by terrestrial communication systems due to economical and geographical reasons. Satellite systems cover almost entire globe [12]. Terrestrial wireless communication has delay that is not noticeable, whereas in satellite communication using geostationary satellites, at an altitude of $36000 \mathrm{~km}$, the users experience a quarter of a second delay. Due to this large delay in Terrestrial communication, users can hear their echo after half a second if no devices such as echo canceller are employed. Again, installation of communication services in any location is easier in satellite system than in terrestrial systems. Figure 1 represents terrestrial communication architecture.

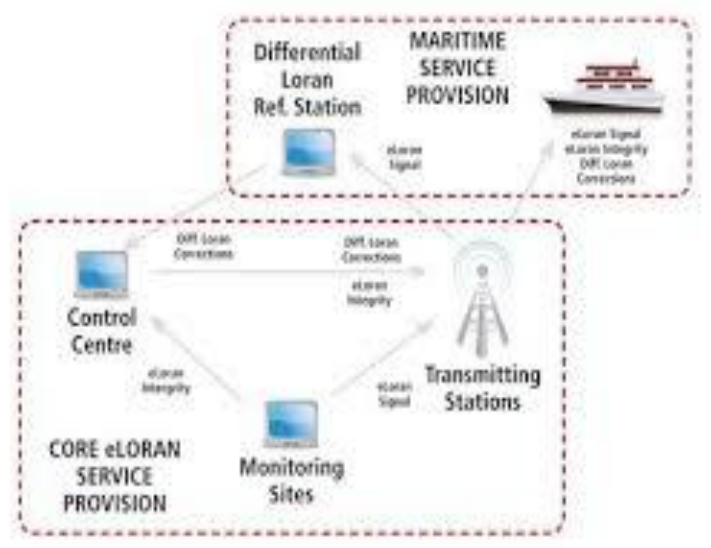

Figure 1: Terrestrial Communication Network Architecture

\section{EVOLUTION OF DVB-RCS STANDARDS}

The earlier development of DVB systems were based on MPEG-2 for digital television and data broadcasting to support encoded and compressed video and audio, and data channels for various information services[5]. This quickly took the center stage and became solutions to all satellite projects for broadcast, broadband and multimedia interactive application for high speed internet and IPTV [12].This evolution quickly lead to the development of second generation DVB standards for cost effective, reliable, secure and efficient. Then, the DVB-S2 was also upgraded to most effective and costless third generation DVB-S2 Adaptive code Modulation (ACM)[7]. The DVB-S is also effectively for Television news gathering via satellite and for distributing television and radio channels to terrestrial transmitters [4]. It is also use to implement VoIP and VDVoIP in maritime and mobile applications. However, DVB-RCS can be optimized in its application with regards to factor relating to space environment and constellation, transmission techniques, satellite antennas systems, VSAT antennas, propagation and interference on space environment. The major consideration for the design and implementation of DVB-RCS solution is the cost-effective provision of a multi-purpose broadband and multimedia space and ground segment capable of supporting a large number of fixed and mobile users for fixed and mobile applications[9].

Below is a family of DVB standards in use:

- DVB-S: It is a Direct to Home (DTH) satellite system for use in the $11 / 12-\mathrm{GHz}$ BSS band, configurable to suit a wide range of transponder bandwidths and EIRPs (the standard is also applied in $\mathrm{C}, \mathrm{Ku}$, and $\mathrm{Ka}$ FSS bands);

- $\quad$ DVB-C: Is a cable delivery system, compatible with DVB-S and used with $8-\mathrm{MHz}$ channels (e.g., consistent with the 625-line systems common in Europe, Africa, and Asia);

- DVB-CS: Is a satellite master antenna TV (SMATV) system, adapted from the standards to serve private cable and communities;

- DVB-T: Is a digital terrestrial TV system designed for 7- to 8-MHz channels;

- DVB-SI: Is a service information system. use in DVB decoder for configuration and to help user navigate DVB bit streams;

- DVB-TXT: Is a DVB fixed-format tele-text transport specification;

- $\quad$ DVB-CI: Is a DVB common interface used in CA and other applications;

- DVB-RCS: Is a return channel by satellite scheme for two-way interactive services within a general broadcast context.

\section{IMPLEMENTATION ARCHITECTURE FOR DVB-RCS \\ 4.1 Space Segment}

The space segment is an integration of three multipurpose constellation geostationary earth orbit (GEO) satellites for global coverage. One satellite for regional coverage has potential for multiple beams while global coverage will require a network of satellites and gate ways. These satellites have operators who provide regional, global and spot beam coverage via geostationary earth orbit satellites to fixed and mobile users. Some of the operators are EUTELSAT, INTELSAT, PanAmSat and others currently provide L, C, Ka and Ku-band constellation suitable for DVB-RCS systems[7].

\subsection{Ground Segment}

The ground segment which includes the Hub, satellite interactive terminal (SIT) and Mobile interactive terminal (MIT) which are designed to integrate DVB-RCS standards for fixed and mobile application is also called the ground station [12]. The Hub communicate via the satellite and interfaces the terrestrial networks served by the satellite and support other services like Terrestrial Broadband, Video Broadcasting, Universal Mobile Systems/General Packet Radio Services(UMTS/GPRS), Asynchronous Transfer Mode (ATM), Terrestrial Telecommunication Network (TTN), Internet Service, Cellular private and Public networks, Virtual Private Networks, and other commercial networks. 
These networks can provide services like Enterprise and private Networks (EPN), Service provider Platforms (SPP), Broadcasting and Content Distribution (BCD), Satellite News Gathering (SNG) satellite Emergency and Security Management (SESM), and Defense Information Management (DIM)

The core component of the ground segment is the HUB made up of the following components:

- Network control centre (NCC) - Is responsible for traffic management, system supervision and protocol handling and can also manage sophisticated bandwidth for return link through four different bandwidth allocation algorithms based on DVB-RCS standards.

- Forward link subsystem - Encapsulation of IP packets into MPEG frames, an MPEG multiplexer and a modulator according to the DVB-S2 standard.

- Return link subsystem - act as massive bank of radio receivers that collects turbo-coded Multiple Frequency Time Division Multiple Access bursts transmitted by all the terminals in the network.

- Reference and synchronization subsystem - Is used for synchronization and information timing for the entire satellite network.

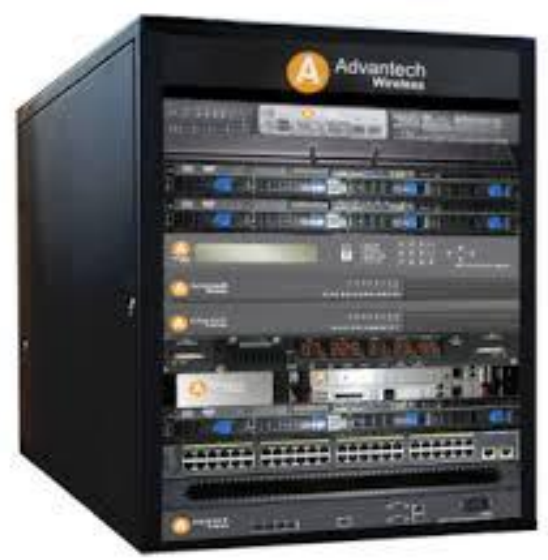

Figure 2: DVB-RCS Hubs from Advantech [7]

The indoor Unit and Outdoor Unit of the satellite and Mobile interactive terminal devices are used to connect remote enduser PC LAN and IPTV to DVB-RCS networks. The installation can be in the office or onboard any mobile system. This communication is a two way multimedia IP via satellite at $\mathrm{C}, \mathrm{Ku}$, or $\mathrm{K}$-band frequencies. The terminals come in scalable choices of performance with variety of range of data IPs and can serve governments, corporations, institutions, private companies or home offices offering open-interface for high capacity satellite broadband.

\subsection{User Segment}

The user segment is made up of a center where data is managed with SITs that are connected to users terminals via LAN or WAN infrastructures. The command and control center is connected via terrestrial network to the DVB-RCS HUB for onward connectivity via satellite to all users anywhere any time.

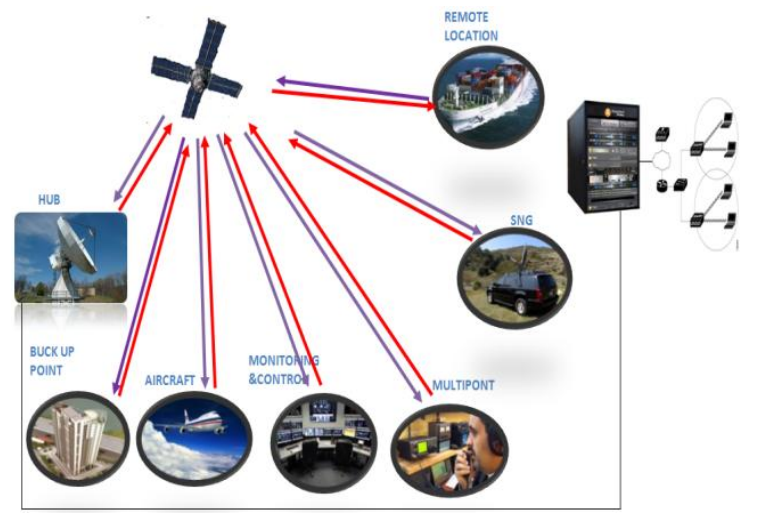

Figure 3: A Network Of Dvb-Res Architecture

\section{GLOBAL MOBILE}

\section{IMPLEMENTATION OF DVB-RCS}

The topology appropriate for this occasion is the star topology which incorporates the Hub to coordinate transmission and access to a central computer. The Hub operates a complex telecommunication facility for the networks life time. The SIT or MIT users can either use the dedicated Hub owned by the user or sheared Hub owned and operated by the service providers for the benefit of multiple user networks. Satellite communication technology has become increasingly cheaper and more accessible for fast, efficient form of communication. DVB-RCS as an interactive network makes it a better choice for a country like Ghana because, it provide multiple service like e-commerce, e-governance, maritime, aeronautical, other mobile and fixed applications to urban, rural and remote or mobile locations if implemented. This would provide an effective solution to communication in both commercial and military applications in urban, rural and remote locations. The DVB-RCS is designed to meet different technical, operational and commercial requirements of a particular transmission network and application. Its contents can be connected via terrestrial telecommunication network and internet to the Hub equipment of GES, employing VoIP, Data over IP and Videoconferencing over IP (VcoIP).

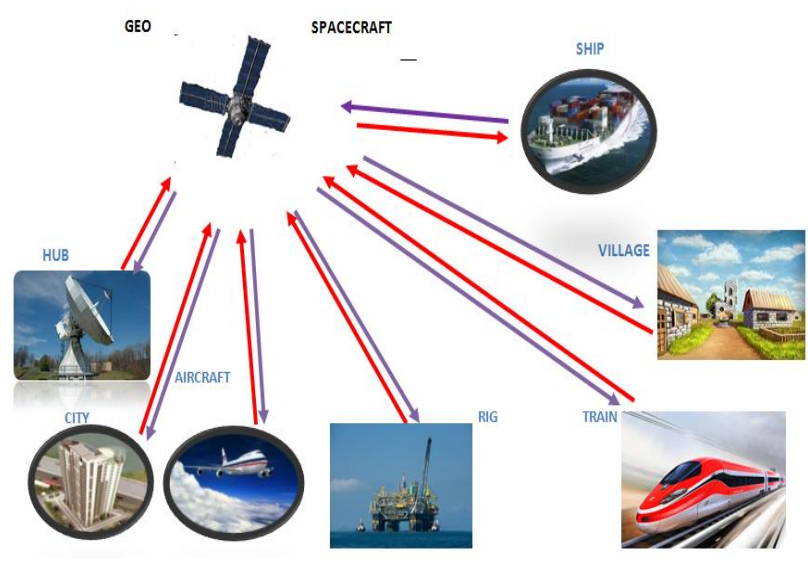

Figure 4: A type of Global DVB-RCS implementation

\subsection{Maritime Application}

In maritime application, Ghana as country trying to improve on communication and surveillance of its territorial waters by 
adopting DVB-RCS to give high quality voice and data communication service. These DVB-RCS offer the best solution for communication by using small SIT terminal antennas to provide VoIP, VDVIoP, Audio, Data and Video (ADV) transmission in remote location on high seas and coastal waters. This communication mode also assist ships in coastal and in high seas with effective navigation and surveillance. The SITs are mounted on ships involve in all form maritime activities, i.e. onshore and offshore drilling, exploration, Fishing, military applications.

\subsection{Mobile Applications}

The DVB-RCS has SITs and MITs which can be mounted cars in remote location by transportable and portable antenna systems for commercial or military applications suitable for two way interactive SNG, VDVoIP and Audio, Data and Video (ADV) transmission. It is also used in hand-held device in digital cellular networks (GSM).The solutions of DVBRCS Mobile and Portable Antenna systems are presented below in figure.

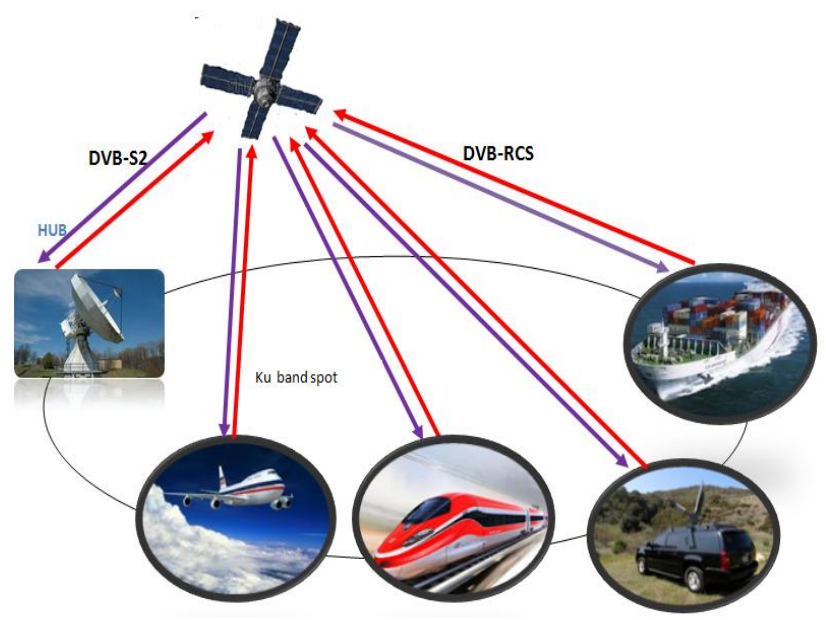

Figure 5: DVB-RCS implementation for mobile users

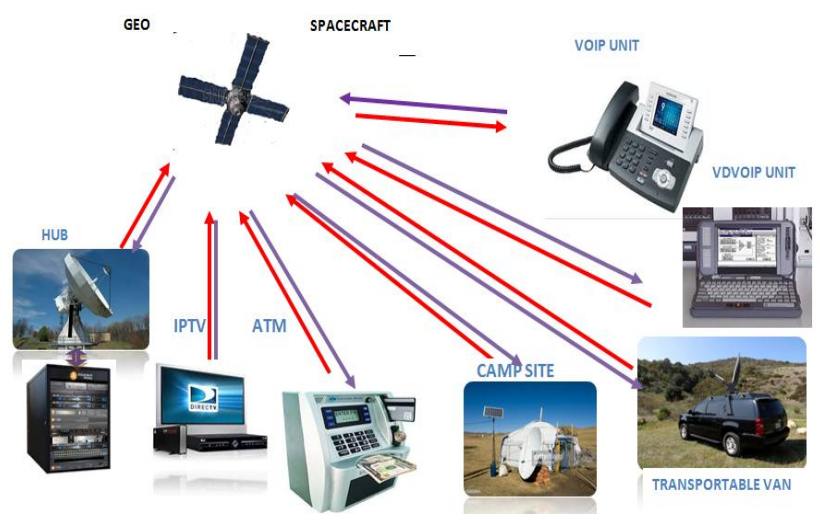

Figure 6: DVB-RCS Network for Rural and Remote applications

In aeronautical services DVB-RCS aims to provide transportable and portable antenna system for VDVIoP, Audio, Data and Video transmission includes passenger voice telephone traffic. However, air traffic control information and airline information are also important, just like that of maritime satellite communications. The service is mostly optimized for trans-Oceanic routes. Moreover, the use of satellite communications to aircraft will always make specific contributions to flight safety and airline efficiency.

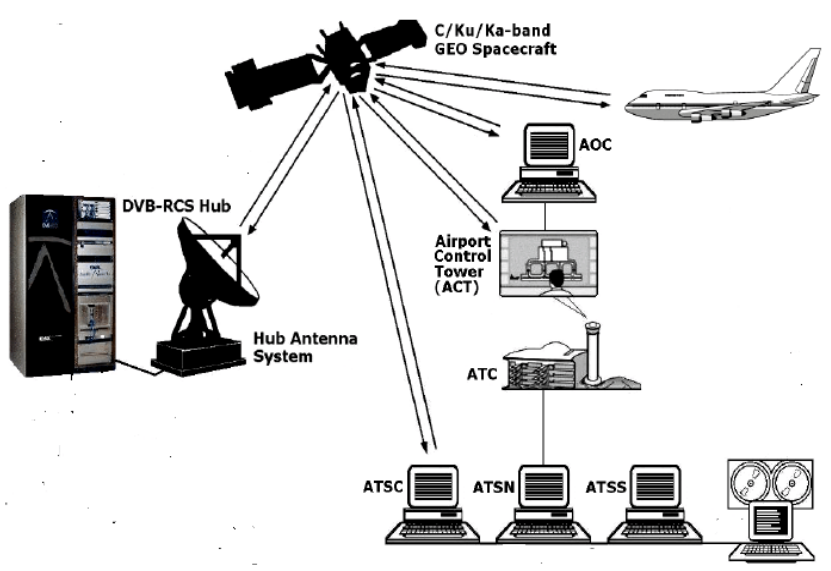

Figure 7: DVB-RCS for Aeronautical application

\section{CONCLUSION}

This paper has outlined current trends in developing next generation of DVB-RCS satellite network and its architecture IP based for improved communication. The DVB-RCS and its Applications delivered in maritime and fixed broadcasting systems have also been analyzed. These Satellite based networks provide a cost effective solution better than current wireless or terrestrial networks, with the lowest cost per bit, better penetration of signals inside buildings, faster internet speed and can integrate all wireless and terrestrial systems. The adoption of DVB-RCS in Ghana will improve communication making it cheaper and accessible, for commercial and military application in urban, rural and remote area. The DVB-RCS also delivers a-two way VDVoIP and multimedia IPTV connectivity between user terminals of the satellite and between user terminals and terrestrial networks. The result from DVB-RCS will improve both mobile and fixed communications to rural, urban and remote within the country. This network can also substitute or integrate all terrestrial or wireless systems and spread the range of telecommunication lines and optical networks across the country. Since it is capable of reaching areas where it is uneconomic for other technologies to reach, its future prospective application can be found in the provision of eeducation, e-banking, tele-medicine, e-commerce, econsulting to improve the economic and general wellbeing of the population in sub-urban, rural and remote areas of the country. It is the platform for emerging economies or third world countries to accelerate development by reaching large audience or the population on real time bases with information.

\section{REFERENCES}

[1] Ariel Pashtan, Wireless Terrestrial Communications: Cellular Telephony, Telecommunication Systems and Technologies, Vol.1

[2] EMS Technologies Canada, EADS Astrium, Operational benefits of mobile DVB-broadband networks,Satlabs DVB-RCS symposium,Noordwijk, Netherlands, September,(2005). 
[3] Ilcev D.S. 2007. Development and Architecture of Eeducation Scenario via DVB-RCS Network in, South Africa, Durban University of Technology.

[4] Acar, G., Kasparis, K. and Thompson, P. The Enhancement of DVB-S2 \& DVB-RCS by adding Additional Mobile User Capability, The Institution of Engineering and Technology Satellite Systems and Applications Network.

[5] Galajda, P., Marchevský, S., Gamec, J., Gamcová, M. And Pillár, S. 2009. Infrastructure for packet based elearning services provided via satellite, Acta Electrotechnica et Informatica Vol. 9, No. 1, 74-80.

[6] Ilcev, D. S. 2008. Satellite Communication, Navigation and Surveillance (CNS), Durban University of Technology (DUT), manuscript, Durban.

[7] Ilcev, D. S. 2005. Global Mobile Satellite Communication for Maritime, land and Aeronautical application, book Springer, Boston.

[8] Millennium Series DVB-RCS VSAT Hub DVB S2 DVB-RCS, Accessed from www.advantechwireless.com

[9] Myeong, S. C., Sun P., Yeonwoo, L. and Seong R. L. 2014. Ship to Ship Maritime Communication for eNavigation Using WiMAX, international Journal of Multimedia and Ubiquitous Engineering, Vol.9, No.4, pp.171-178.

[10] Pollack, M. 2006. The Key Benefits and Advantages of DVB-RCS/S2 Technologies, Advantech, Montreal.

[11] Sanjay, j. and Kinshuk. 2008. Analysis OF Qos For DVB-RCS-Based IP Network, campus wide information systems, vol.25. pp. 4-7.

[12] llcev, S.D. 2009. Satellite DVB-RCS Standards for Fixed and Mobile Commercial and Military Applications, Durban University of Technology (2009).
[13] Sithamparanathan, K., Karina, G., Laurent, R., Tinku, R. Aerial Terrestrial Communications: Terrestrial Cooperation and Energy-Efficient Transmissions to Aerial-Base Stations, IEEE Transactions on Aerospace and Electronic Systems.

[14] Truchly, P., Ocel, M. 2008. End-to-end Packet delay in LEO satellite Constellations, $15^{\text {th }}$ international conference on systems, and signals and image processing, IWSSIP'08, JUNE 2008, Bratislava, Slovak republic, pp 515-518

[15] Vasantha K. N.G., Mohanchur S., Vishal, A., Chaniara, B.P., Mehta, S.V., Palsule, V.S., Dasgupta, K.S. 2011. Digital Video Broadcast Return Channel Via Satellite(DVB-RCS) Hub for satellite Based e-learning, International Journal of Multimedia \& its applications(IJMA)Vol.3,No.1,February 2011

[16] Vasantha, K .N. G., Vishal, A., Mohanchur, S. 2010. A method for processing a plurality of internet Protocol (IP) Packet of a DVB-RCS Hub.

[17] Webpages: "GEO Satellite Operators: Intelsat, PanAmSat, SES-NewSkies \& Eutelsat, 2008.

[18] Liang, X., Ong, F. L. C., Pillai, P., Chan, P. M. L., Mancuso, V., Koltsidas, G., Pavlidou, F. N., Caviglione, L., Ferro, E., Gotta, A., Cruickshank, H., Iyengar, S. and Fairhurst, G.. 2007. Fusion of digital Television, broadband internet and Mobile Communication-Part II: Future service Scenarios, International Journal of Satellite Communications and Networking, 25:409-440.

[19] Young, C. P. 2008. Terrestrial communications system design and MOE factors, International Journal of Management Science and Engineering Management, Vol. 3, No. 3, pp. 232-240. 